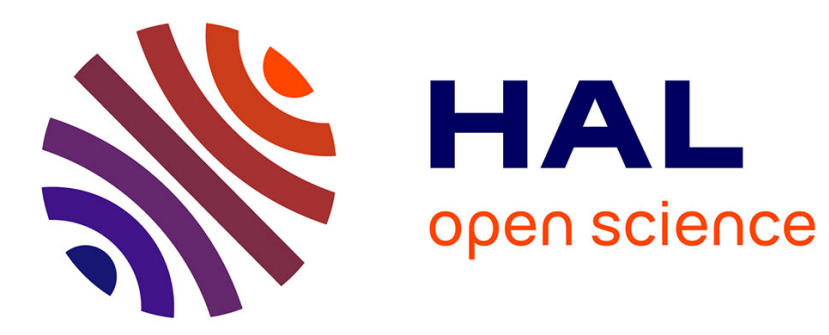

\title{
Should phenomenological approaches to illness be wary of naturalism?
}

Juliette Ferry-Danini

\section{To cite this version:}

Juliette Ferry-Danini. Should phenomenological approaches to illness be wary of naturalism?. Studies in History and Philosophy of Science Part C: Studies in History and Philosophy of Biological and Biomedical Sciences, In press. hal-01682974v3

\section{HAL Id: hal-01682974 \\ https://hal.science/hal-01682974v3}

Submitted on 26 May 2018

HAL is a multi-disciplinary open access archive for the deposit and dissemination of scientific research documents, whether they are published or not. The documents may come from teaching and research institutions in France or abroad, or from public or private research centers.
L'archive ouverte pluridisciplinaire HAL, est destinée au dépôt et à la diffusion de documents scientifiques de niveau recherche, publiés ou non, émanant des établissements d'enseignement et de recherche français ou étrangers, des laboratoires publics ou privés. 


\title{
Should phenomenological approaches to illness really-be wary of naturalism?
}

\section{Juliette Ferry-Danini}

\section{Sorbonne Université}

\section{ferry.danini@gmail.com}

\begin{abstract}
In some quarters within philosophy of medicine, more particularly in the phenomenological approaches, naturalism is looked upon with suspicion. This paper argues, first, that it is necessary to distinguish between two expressions of this attitude towards naturalism: phenomenological approaches to illness disagree with naturalism regarding various theoretical claims and they disapprove of naturalism on an ethical level. Second, this paper argues that both the disagreement with and the disapproval of naturalism are to a large extent confused. It then offers some proposals to set up an agenda for future collaboration.
\end{abstract}

Key words: naturalism; anti-naturalism; phenomenology; medicine; health and illness

\section{Introduction}

Voices are often raised against what is called the biomedical model. In 1977, for instance, George Engel raised concerns over the biomedical model of disease, and argued for a model considering psychological and social, rather than exclusively biological features of illness (Engel, 1977). This kind of critique is sometimes aimed at naturalism, sometimes at science in general, and it is characteristic of several fields in and outside the philosophy of medicine; for instance, narrative medicine, psychology, and nursing studies. The concern expressed in these various fields is often similar. As James Marcum asked, "[w]hy should modern medicine provide such competent technical care and yet fail to provide the humane care patients also need?"(Marcum, 2008, p. 393). Phenomenological approaches to medicine and illness are one of the more recent approaches exhibiting such a wary attitude towards naturalism. Havi Carel has thus declared that her "main discomfort with the orthodox concept of illness is that it originates in a naturalistic approach" $(2008,9)$. Phenomenological approaches to illness have been featured in recent handbooks of philosophy of medicine (Schramme \& Edwards, 2017; Solomon, Kincaid, \& Simon, 2017) and monographs from the field have just been published (Carel, 2016; Svenaeus, 2017). Key proponents of what is sometimes called the "phenomenology of medicine," or “phenomenology and medicine," include S. Kay Toombs (1987, 1988, 2001), Fredrik Sveaneus (2000, 
2001, 2009, 2013, 2014) and Havi Carel $(2008,2011,2012,2016)$; "phenomenology of illness" is also used as a label. Phenomenological approaches to medicine or illness, henceforth PhenoMed, have by now secured a widespread appeal in the philosophy of medicine landscape. Despite this popularity, there is little work engaging critically with the main claims of this relatively recent trend. This paper is a contribution to this kind of critical examination (in the line of Gergel, 2012 and Sholl, 2015), by addressing one important aspect of the PhenoMed approach: how it situates itself towards naturalism, and how it seems to be wary of or uncomfortable with it. Commenting on the recurrent attacks on naturalism in general, Daniel Andler has pointed out that "everybody targets or figures she's targeting something precise, has made up her mind long ago, and doesn't care much for entering again that same old never-ending debate" (Andler 2016, 11). This diagnosis fits well with the attitude of PhenoMed towards naturalism. The main aim of this paper is thus to emphasise or to point towards such an attitude, which I call, for lack of a better word, wary of naturalism; the aim is to take this attitude at face value and try to characterise it. Why is PhenoMed wary of naturalism? In other words, what are the issues with naturalism, according to PhenoMed, which justify this attitude? Is this attitude homogenous in PhenoMed or does it come in variants? Does PhenoMed criticise, disagree with or disapprove of naturalism? Since phenomenology is probably one of the most convincing standard bearers of the criticism of naturalism in medical humanities, these questions are especially important. Furthermore, at a time when the debate between naturalism and normativism in the philosophy of medicine seems to be moving beyond its former cartoonish stage (see for instance Kingma, 2014), it seems important not to let this kind of wary attitude hover over the conversation without providing articulated reasons. In brief, shoulddoes PhenoMed-reallyought to be wary of naturalism? To quote Ernest Nagel,

\footnotetext{
the conception of philosophy as a struggle between competing systems is especially sterile when the "ism" defended or attacked covers as miscellaneous an assortment of not always congruous views as fly the banner of naturalism. (Nagel, 1954, p. 5)
}

After a brief overview of the main claims of PhenoMed, where I distinguish between descriptive and prescriptive claims, I turn to examine the attitude towards naturalism that lies at the foundation of some of these claims; I argue that this attitude needs to be spelled out in two important ways. First, it can be understood as a form of scepticism or disagreement regarding a series of philosophical claims ascribed to naturalism. Section 3 is thus an attempt at characterising this disagreement. In order to clarify this disagreement, I argue that several claims are ambiguously attributed by PhenoMed to naturalism and become possible targets for or objects of their disagreement. I review several such plausible targets: general epistemological or metaphysical naturalist claims, reductionist naturalism, the biomedical model and the scientific approach. I argue that on top of this ambiguity, each target faces some argumentative limits. 
In the second part of this paper, I argue that there is another interesting way of spelling out PhenoMed's wary attitude towards naturalism. I argue that it is best understood as an imputation of moral failure. In this debate, naturalism becomes a thick concept (Foot, 1958; Ryle, 1968; Williams, 1985; Andler, 2016), ${ }^{1}$ i.e. a concept featuring both descriptive and evaluative traits. Characterising PhenoMed's attitude towards naturalism in this moral or practical way helps to understand the motivations of PhenoMed for introducing phenomenology in the field of philosophy of medicine, and it usefully emphasises PhenoMed's prescriptive goals.

Finally, in the last part of this paper, I hope to foster a dialogue between PhenoMed's proponents and naturalism by suggesting how PhenoMed, depending on its official goals, could go beyond - or clarify - its attitude towards naturalism. I suggest several options for PhenoMed to move forward.

\section{A few words about PhenoMed's descriptive and prescriptive claims}

PhenoMed offers a series of claims about illness and medicine, some of which are prescriptive, some of which are descriptive. Although this paper will not argue directly against these claims, it is useful to give a brief overview of the literature. Among the proponents of PhenoMed, it is often argued that phenomenology should be used to describe the subjective experience of illness. For instance, the distinction between the physical and the lived body (found in Maurice Merleau-Ponty's phenomenology) is crucial for Havi Carel, who argues that in illness, it is not only our physical body that is at stake, but our whole world. She explains that in illness, our social world, our perceptions, and our habits are disrupted. This description is then sometimes used to give a definition of illness as a disturbance in one's lived experience. The proponents of the approach go on to argue that this phenomenological description will provide a new and better basis for medicine and clinical practice. This is the prescriptive part of their claims: phenomenology is believed to be able to improve medicine. Before going further, an important distinction must be mentioned: the distinction between medical science and clinical practice. ${ }^{2}$ This distinction is implicitly endorsed by all proponents of PhenoMed who endorse the neighbouring distinction between illness and disease. Positioning themselves by contrast to naturalism, their position seems to be that medicine should not overall be reduced to medical science. Medicine should be humanised in the sense that a new emphasis should be put on clinical practice, by means of bringing forward phenomenology. This belief takes different shapes. First,

\footnotetext{
${ }^{1}$ Foot has introduced the idea that some concepts have both evaluative and descriptive traits; Williams has coined the term "thick concept" drawing from Gilbert Ryle's notion of "thick description"; Andler has referred to naturalism as a thick concept.

${ }^{2}$ I thank an anonymous reviewer for this reminder.
} 
there is the idea that health professionals will understand their patients' experience of illness better thanks to its phenomenological description. It would create, according to Carel, a "shared meaning of illness" (2011, p. 42). Second, there is the belief that phenomenology should also help patients to describe and understand their own illness better, which in turn, should help practitioners come to know their needs and offer them "greater benefit" (2011, p. 43). Overall, with this focus on the illness experience and the patient, phenomenology is believed to lead to the humanising of medicine. A lot could be said about these various claims; however, this is not the purpose of this paper. What matters here is why phenomenology is argued to be useful for humanising medicine, or in other words, what phenomenology brings to the philosophical debate which other approaches do not and therefore, why it is distinguished among other approaches. The proponents of PhenoMed argue that phenomenology is crucial for enabling one to go beyond the biomedical model, also called biomedicine or more simply, naturalism. Take, for instance, what Havi Carel writes at the beginning of her book:

\section{I found phenomenology - the description of lived experience - to be the most helpful approach to augmenting the naturalistic account of illness. (Carel, 2008, p. 10)}

In other words, many proponents of PhenoMed seem to have chosen to embrace a phenomenological approach because they believe naturalism is not an adequate approach on its own or overall. If phenomenology is valued for being able to go beyond naturalism, it is mainly because naturalism is argued to be at the root of many problems, and as such is undesirable. Indeed, the defence of phenomenology typically begins by spelling out a certain opposition - varying in strength, as we shall see - to naturalism. This opposition is therefore a cornerstone of their approach and is key to understanding the general relevance of their approach; this is why understanding and characterising this wary attitude towards naturalism in PhenoMed is crucial.

\section{Examining PhenoMed's disagreement with naturalism - What is the disagreement between PhenoMed's and naturalism?}

Given the rhetorical importance for PhenoMed to positioning oneself towards naturalism, , it is unsurprising to find the expression of this wariness recurring like a leitmotif in the literature. For instance, Kay Toombs declares that humanising medicine "can only truly succeed if the anatomical/pathological model of illness (the biomedical model) is superseded by a paradigm which incorporates an understanding of illness-as-lived" (Toombs, 1987, p. 235). Carel writes that her "main discomfort with the orthodox concept of illness is that it originates in a naturalistic approach" (2008, 9), while Fredrik Svenaeus is arguing for "a focus on the ways of the lived body, in contrast and in addition to the biological ways of the body (...)" (Svenaeus, 2009, p. 55). It is important to note that the disagreement with naturalism comes in varying strengths. As we shall see in more detail, Carel's 
work, for instance, shows more of a "discomfort" (Carel, 2008, p. 9), whereas Svenaeus, in his most recent work, describes his phenomenological approach as a vehemently "anti-naturalistic" project (Svenaeus, 2017, pp. 2-3). However, as the above quote by the same author shows, the strength of their wariness of naturalism may vary from publications to publications and remain ambiguous because not completely articulated. Indeed, what exactly is naturalism and what are its shortcomings? A clarification is needed to understand where the disagreement lies.

The most obvious way to characterise this situation is to understand PhenoMed's wary feeling of naturalism as being akin to an epistemological or philosophical disagreement. Quite simply, it seems that PhenoMed does not agree with whatever naturalism's philosophical claims are, whether these are general or particular claims. Before trying to spell out this disagreement, it is necessary to turn to understanding how naturalism is defined by PhenoMed proponents. The first problem is that this definition is largely ambiguous, mostly because, as often when it comes to naturalism, its meaning is taken for granted. In what follows, several conceptions of naturalism, as plausibly targeted by PhenoMed, are detailed and reviewed.

\subsection{Why is PhenoMed uncomfortable with naturalism and in what sense? An attempt at clarifying PhenoMed's disagreement with naturalism}

Jonathan Sholl has argued that although it is common in philosophy to distinguish between different types of naturalism, such distinctions are not found in PhenoMed literature (2015). It is especially customary to distinguish between two kinds of naturalism: a metaphysical naturalism, or the thesis according to which nothing exists in the world such that it could be left unexplained by science; and epistemological naturalism, or the thesis according to which science has a priority in the knowledge and the explanation of the things in the world. In the case of medicine, metaphysical naturalism could, for example, claim that only disease as a biological fact exists; epistemological naturalism, by contrast, could claim that science (in our case, biology) has the priority in the explanation of disease - in other words, as Sholl has suggested, that science can demarcate between health and disease (2015). This standard distinction, however, is not addressed by what is probably the most precise definition of naturalism one can find in the PhenoMed literature. Havi Carel writes that naturalism is

\footnotetext{
a label for a broad spectrum of views saying, roughly, that natural or physical facts are sufficient to explain the human world. On a naturalistic view, illness can be exhaustively accounted for by physical facts alone. This description is objective (and objectifying), neutral and third-personal. Naturalistic descriptions of illness exclude the first person experience and the changes to a person's life that illness causes. (Carel, 2008, pp. 9-10)
}

Following Sholl's argument, a first problem in trying to identify the philosophical naturalist claims criticised and targeted by PhenoMed is thus that the very nature of these claims - metaphysical or 
epistemological? - is not clear. However, it should be noted that it is not always clear either, on the naturalist side, whether and when epistemological or metaphysical claims are put forward; hence, weakening Sholl's initial argument. Furthermore, in any case and to Sholl's own acknowledgement, it is possible to find PhenoMed's a more charitable target.

Proponents of the phenomenology of medicine often write that naturalism "reduces" illness to something physical, or that naturalism only cares for the "purely" biological aspect of illness. On the basis of these recurrences, Sholl has suggested that what seems to trigger PhenoMed's criticism is not any type of naturalism, but something like reductionist naturalism (2015). More specifically, they appear to be targeting reductionist physicalism, the thesis according to which nothing exists in the world that cannot be explained and reduced to physical facts (here, biological facts). For instance, Carel seems to target such a reductionist thesis when she writes that illness is not "only physical but also psychological, social" and so on (Carel, 2011, p. 42). When Svenaeus writes that according to naturalism, "there will consequently be no illness, no medical suffering so to say, without a disease", he's targeting a textbook definition of reductionist physicalism. Such a physicalist approach would claim that there is no such thing as a disease or illness without a biological dysfunction that explains it. Here is the full quote:

\footnotetext{
if a claim of a certain diagnosis does not have any demonstrable [...] link to a specific biological abnormality, doctors will generally resist admitting it is a real disease. In this sense many, maybe most, doctors are, I think, naturalists [...]. For the standard doctor there will consequently be no illness, no medical suffering so to say, without a disease, even though the whole story of the illness in question cannot be solely determined by biological factors. (Svenaeus, 2013, p. 223)
}

Sholl points out that the proponents of PhenoMed, although right to argue that this type of naturalism is implausible regarding health and disease, end up making a strawman of naturalism, i.e. a convenient caricature of naturalism which is easy to target (Sholl, 2015). Indeed, naturalism needs not be stuck with an old-fashioned mechanistic or biological-only approach, improper for the study of human beings, their experiences and behaviours. Several scientific approaches study those human aspects. For example, in the field of medicine, public health, while naturalistic and statistical, takes into account social and economic health determinants. Naturalism needs not amount to reductionist physicalism, and proponents of PhenoMed seem to be ignoring this. Missing the distinction between epistemological and metaphysical naturalism may be a possible cause of that attitude.

However, contra Sholl, there could be a more charitable interpretation of this situation, in which proponents of PhenoMed are led to targeting reductionist physicalism. This interpretation echoes the degree of strength that characterises the attitude towards naturalism in PhenoMed. Recall that some proponents of PhenoMed do not wish to reject naturalism completely, but solely to 
augment it (notably, this seems to be the case for Carel). Criticising reductionist physicalism might be a way to endorse a more modest type of naturalism, for instance epistemological naturalism, and accept the scientific approaches that study human aspects. On this more charitable interpretation, Havi Carel's position, notably, does not completely reject naturalism. The feeling of discomfort with naturalism expressed by Carel could be justified by the need of putting distance between oneself and these caricature views of naturalism, doing so in order to offer a new approach to illness that cannot be associated with these views. If this attitude is understandable, because PhenoMed wants to put forward a view of illness that is not usually associated with these caricature views of naturalism, ${ }^{3}$ it can nonetheless be viewed as a slippery slope. Carel still risks, on this view, to paint naturalism as a strawman. Wanting to augment a strawman remains as problematic as wanting to criticise it. Of course, painting naturalism as a strawman will be more problematic for Svenaeus, , who explicitly declares his approach to be anti-naturalistic. However, although a slippery strategy, targeting reductionist physicalism will not be a major problem for the PhenoMed proponents who seem ready to endorse a modest form of naturalism. It will be quite simple to set things right. Nonetheless, if one wishes to retain a global opposition to naturalism, i.e. if one truly believes that even a more modest form of naturalism is false, lacking or inadequate, it will have to be spelled out in different terms to avoid targeting a strawman; even on the count of wishing to augment it. This will be addressed at the end of this paper.

\subsection{Is the third-person perspective the crux of the disagreement about naturalism?}

Reductionist physicalism isn't the sole plausible target for naturalism that we find in PhenoMed. Looking at what PhenoMed proponents offer by opposition to naturalism helps us spell out such plausible targets. They often write that the naturalist approach forgets the "subjective experiences" (Carel, 2011, p. 33), the "lived experience" (2011, p. 40), "the first-person perspective" (Carel, 2008, p. 13) or the "life-world perspective of the patient" (Svenaeus, 2009, p. 55). For instance, according to Carel $(2008$, p. 10), a naturalistic approach to depression would only describe depression in terms of neurological dysfunctions and neurotransmitters. Phenomenologists like her, on the other hand, would be interested in the subjective and psychological aspects of depression. Could it mean that according to the phenomenology of medicine proponents, a naturalistic approach would not account for psychological aspects but only for the biological aspects of illness? Would it be why, for Carel, naturalism is understood to be "neutral"? (Carel, 2008, p. 10). Yet Svenaeus insists that the difference between the phenomenological understanding of illness and the naturalistic understanding of disease

\footnotetext{
${ }^{3}$ I thank an anonymous reviewer for this suggestion.
} 
is not a difference of depth but comes from the difference of perspective between the first person and the third-person perspective (Svenaeus, 2013, p. 224). Could it be then that what defines a naturalistic approach, according to the proponents of PhenoMed, is that it is a kind of non-subjective third-person point of view? In his latest work, Svenaeus takes it further by defining the naturalistic approach as the "third-person (or, rather, non-person) perspective of science" (Svenaeus, 2017, p. 2).

The issue is that, despite recurrent and explicit criticisms of metaphysical dualism, it is never clear whether PhenoMed's proponents distinguish between the subjective experience and the psychological experience (likewise, whether they distinguish between the third-person point of view and the point of view of biological sciences). Both seem to be used in indistinguishable ways, such that when one refers to the subjective experience of illness, one seems to refer to the psychological, emotional and social aspects of a human life (Carel adds temporal and existential as well, see (Carel, 2011, p. 42). In this context, it is not surprising that Kay Toombs explicitly targets Descartes's mechanistic approach: she aims for the phenomenological approach to complete naturalism by bringing forward the "mind"-related part of illness (Toombs, 1988, p. 201). By opposition, the "thirdperson" point of view, or worst, the "non-person" point of view of science (Svenaeus, 2017, p. 2), is often conflated with the point of view of biological science. References to "biological functions"(Svenaeus, 2017, p. 2) or "mechanistic causal explanations" (Carel, 2017) are systematically presented as the main opposition to what the first-person subjective experience brings. For instance, Dorothée Legrand writes that "evidence-based medicine is thought to favour exclusively the body as object" by opposition to the phenomenological approach that focuses on the body as being "distinctively subjective" (Legrand, 2017, p. 463). Despite previous protestations voiced by Svenaeus who writes that "illness is not meant as a psychological characterisation of the life of the person, in contrast to the 'real' diseases of somatics"' (Svenaeus, 2001, p. 88), the ambiguity remains.

Contrary to explicit endorsements of anti-dualism by PhenoMed proponents, I argue that what we are left with is a dualistic picture: naturalism is left dealing with the bodily side of illness and phenomenology dealing with the psychological side of illness. The worry is that PhenoMed's warning against dualism remains only verbal. This dualistic framework is problematic if it is a metaphysical dualism between mind and body; it is hard to square, for example, with Toombs's criticisms of Cartesian dualism. It also contradicts the phenomenological tradition (most notably Martin Heidegger's and Maurice Merleau-Ponty's positions) which is endorsed by the proponents of the phenomenology of medicine (Carel, 2016, p. 7). Anti-dualism is also explicitly endorsed by Svenaeus 
$(2017$, p. 2). In the introduction to his new book, in order to illustrate this anti-dualistic view, Svenaeus writes that it goes against the "picture of a soul living in and directing the ways of the body like some ghost in a machine" $(2017$, p. 2) thus echoing Descartes's own famous comparison in the Metaphysical meditations. ${ }^{5}$ Descartes's argument, however, was meant to illustrate the union of mind and body -a position which does not imply that they are the same substance or, in other words, which does not reject dualism. Despite PhenoMed's careful declarations against metaphysical dualism, a dualistic type of approach thus remains tangible in their writings: distinguishing facts from values, disease from illness, science from art, object from subject, the third-person point of view from the first-person point of view. It is present in Carel's most recent book, in spirit if not in essence, and maybe in spite of her, notably where she argues that her topic is "about the experience of illness, not the facts of disease [which] falls within the domain of empirical science" (Carel, 2016, p. 17). It could be that declaring to wish to augment naturalism explains this uncomfortable position, illustrating how it might not be the best strategy for PhenoMed to follow.

In the end, once again, it is not clear whether the proponents of the phenomenology of medicine are targeting a metaphysical position (here the position reducing mind to body, experiences to biological facts), an epistemological position (the position ignoring the first-person perspective) or, alternatively, both. The issue, of course, is that this target is not properly sketched out. Failing to identify this target, however, isn't without consequence, since, in turn, it is difficult to understand what the proponents of the phenomenology of medicine wish to complement or bring forward with their own approach. In brief, is the phenomenology of medicine a metaphysical, an epistemological approach or alternatively, in the spirit of the later Heidegger, something else altogether and none of the above ${ }^{6}$ Based on their critique of naturalism, it remains ambiguous and in need to be addressed in a more explicit manner.

\subsection{The gap between philosophical and empirical claims}

There is another way the naturalist target painted by PhenoMed may be akin to a strawman. Even putting the chosen depiction of naturalism aside, it is one thing to criticise and define a naturalist philosophical approach, but quite another to ascribe this position to physicians or to medicine. It doesn't seem enough to claim that "many, maybe most, doctors are (...) naturalists" (Svenaeus 2013, 223), that "generally speaking, the clinician understands illness as a biological process (...)" (Carel,

\footnotetext{
4 "[P]henomenology, despite its anti-dualism, has also from its beginnings, been an anti-naturalistic project; that is, the phenomenologist would contest any attempt to reduce experience to material processes only."

5 Indeed, even the reference to Ryle granted, is it not strange to declare that the "transgression" of phenomenology (Svenaeus 2017, 2) consists in an argument made by Descartes?

${ }^{6}$ I thank an anonymous reviewer for this suggestion.
} 
2011, p. 42) or that "[m]edicine has, for the most part, adopted a "Cartesian" paradigm of embodiment" (Toombs 1988, 201). Ascribing a philosophical position to a whole field - and claiming for instance that medicine is physicalist and reductionist - seems unwarranted, especially if presented without argument. I take it that whether most doctors endorse reductive physicalism - or any other type of naturalism - is an empirical question, not a philosophical one. It is at best a slippery claim. On top of this methodological caveat, it seems strange to argue that nowadays medicine, in rich countries at least, merely cares for biological aspects of illness. For when there are no biological causes found or and no medical treatment possible, the physician is still meant to continue caring for her patient. Furthermore, many health professionals conduct psychological or social prevention. In her most recent book, Carel acknowledges that there are counter-examples to her description of naturalism in medicine, but sticks to her critique (Carel, 2016, p. 16), only adding that those areas of medicine that do not focus on the biological aspect of disease are "perceived (...) as less prestigious" by medical students and professionals. It is not clear why the fact that they are less prestigious - if it is indeed the case - implies that they are somehow outside of modern western medicine.

\subsection{Yet another plausible target for PhenoMed: the scientific "biomedical model"?}

It might be possible to reformulate once more PhenoMed's scepticism regarding naturalism, in the hope of avoiding a strawman target. In her most recent book, Carel seems to have a somewhat different target in mind (2016). Although she still talks about the need to complement "a naturalistic account of disease" (Carel, 2016, p. 1), her definition of naturalism seems to have shifted towards science. The problem of naturalism, she says, is that it views illness solely "as a subject of scientific investigation" (2016, p. 1). "It is not enough," she says, "to see illness as an entity in the world that can be studied with the tools of science" $(2016$, p. 1). However, what we find next is not an argument against science or the scientific approach to illness and disease, which would have been akin to another critique of the third-person point of view of naturalism. What we find is a description of the "western dominant medical view" of modern medicine, which is described as "scientific and rel[ying] heavily on understanding discrete mechanisms and functions in a detailed, if piecemeal, fashion" (Carel, 2016, pp. 15-16)..$^{7}$ What does "medicine" here refers to? If it refers to medical science, then it would seem that Carel wishes to complete medical science by another type of approach. If it means clinical science, then it would seem that Carel argue that contemporary modern clinical medicine is solely based on biological science. However, medicine - whether understood as medical science or clinical medicine Is arguably not reducible to the science of biological mechanisms: medicine is also epidemiology

\footnotetext{
${ }^{7}$ Carel describes a world view as a set of assumptions that drives our everyday understanding of medicine. I leave open the question of whether it is possible to determine such a world view from a philosophical point of view.
} 
(focusing on statistical data), public health (focusing on socio-economical determinants), evidencebased medicine (focusing on levels of evidence, most notably clinical trials and meta-analyses), and so on. Some have defined medicine as including the whole health system. William Stempsey writes, for instance, that "medicine" is akin to a shorthand for "healthcare" (Stempsey, 2008, p. 380). It is not even clear that biology is the main scientific framework for medical science: evidence based medicine - which could arguably be taken as better reflecting the western world's overall medical outlook view - is scientific, but it does not focus on "piecemeal" biological dysfunctions, as Carel writes (Carel, 2016, p. 15). Furthermore, it is probably not a good strategy to base one's criticism of naturalism on an abstract medical model that is detached from the way health systems are indeed organised. It is also problematic to assume that there is such a thing as a unified western medical model (see Rose, 2007). ${ }^{8}$ For instance, does the French healthcare system, which funds homoeopathic and other nonbiomedical practices, exemplify a biomedical model solely focused on a scientific and biomedical model of illness? This is not trivial, especially if one wishes to focus on the experience of illness: is this experience the same in different western countries?

In hopes of clarifying the wary attitude towards naturalism found in the works of PhenoMed's proponents, I have reviewed a number of plausible causes for this attitude which can be identified in their writing. . One issue is that by ignoring the important distinction between epistemological and metaphysical types of naturalism, PhenoMeds is risking making a strawman out of naturalism, as pointed by Sholl (2015). However, although slippery, picturing naturalism as an implausible reductionist type of physicalism, leaves the door open for endorsing a modest form of naturalism. Despite this possibility, PhenoMed proponents invariably continue to express concerns about manifestations of naturalism, notably the beliefs of doctors, science and the biomedical model. Overall, they seem to conflate naturalism with medical science, biology, and more largely science. These targets have all been shown to be problematic in some respects. The underlying reason for these difficulties is that it remains unclear what parts of naturalism PhenoMed is uncomfortable with and why.

\section{Being wary of naturalism: a question of context}

To whom is addressed PhenoMed's wary attitude towards naturalism? By this I mean, which philosopher? Is it Descartes (mechanism), as it is sometimes suggested by Kay Toombs (Toombs, 1988, p. 201)? Or is the critique addressed to the main proponent of naturalism in the philosophy of

\footnotetext{
${ }^{8}$ Rose writes, "Medicine has no essence, be it epistemological (there is no single model), political (the power of medicine cannot be reduced to social control or the management of social problems), or patriarchal (medicine and medics do not merely seek control over women and their bodies)" (2007, p. 700).
} 
medicine, Christopher Boorse? In some places, Carel (2008) and Svenaeus (2013), indeed seem to situate their criticism in the main debate of the philosophy of medicine: the debate over the concepts of health and disease and between naturalism and normativism, where Boorse is a major actor. For instance, recall that Carel wishes to complement the "naturalistic account of disease" (Carel, 2016, p. 1). In her first book on the topic (Carel, 2008, pp. 9, 13), she also locates herself in the debate between naturalism and normativism (and criticizes both), writing that while "[n]aturalistic descriptions of illness exclude the first person experience and the changes to a person's life that illness causes" (Carel, 2008, p. 9), the normativist position misses the same perspective by "se[eing] illness as something that must be socially evaluated as negative and not just a physiological process (...)" (Carel, 2008, p. 13). Engaging with and addressing their criticism to Boorse also means that the proponents of PhenoMed aim to locate - at least rhetorically - their position within the debate between naturalism and normativism about the definition of illness and disease.

\subsection{PhenoMed's attempt at engaging with Christopher Boorse's naturalism}

Does PhenoMed succeed in situating itself in comparison with the naturalistic side of the debate about the concepts of health and disease? Answering this question is important to contextualise PhenoMed's attitude towards naturalism. When clarifying the overall wary feeling towards naturalism in PhenoMed, I concluded that it was unclear whether its proponents were discussing metaphysical or epistemological issues, although the description of a metaphysical and reductionist approach was the most charitable and plausible target. This raises an initial problem: the canonical debate between naturalism and normativism in the philosophy of medicine is not a metaphysical debate about the reality of existence of illness and disease; rather, it is a debate about the concepts of health and disease and how to demarcate between the two. When targeting metaphysical questions, proponents of PhenoMed necessarily do not locate themselves in that debate. The second problem is that criticising reductionist physicalism fails to criticise Christopher Boorse's position, for the simple reason that Boorse endorses neither a metaphysical nor a reductionist position. It is just not true that according to Boorse's naturalism, there will be no illness if there is no biological dysfunction. Indeed Boorse's main theoretical move is to distinguish between disease (the scientific concept of a biological dysfunction) from illness (the practical and normative concept of the illness experience), not to reduce the second to the first (Boorse, 1975). Consequently, as Sholl has argued, the strategy of PhenoMed, to complement naturalism with phenomenology (the description of lived experiences), ends up looking very similar to the position of Christopher Boorse (Sholl, 2015, p. 392). According to Sholl, it goes even further than that. As he points out, the definition of what counts as "healthy" in the phenomenological literature is often based on what is "habitual" and "normal" (Carel, 2011, p. 39; Svenaeus, 2013, p. 98), 
which happens to be quite like the way it is defined in Boorse's approach. Despite its resistance to naturalism, then, PhenoMed ends up embracing a similar position to their naturalistic counterparts.

\subsection{Situating oneself in relation to naturalism and the goals of PhenoMed}

So far, this paper has identified several issues with PhenoMed's disagreement with naturalism. It is important to underline why these issues are a problem for PhenoMed. Recall that I explained that this disagreement with naturalism is useful in that it helps PhenoMed justify the introduction of phenomenology in the discussion, its relevance and novelty. However, if this disagreement with naturalism is misplaced and/or ambiguous, then it can no longer work as a good justification for phenomenology. That is why proponents of the phenomenology of medicine will have to address this issue. It should be noted that the alleged inadequacy of naturalism is not the only justification for the relevance of phenomenology given by the proponents of the field (however it always seems to be the first). Notably they also argue that phenomenology has a special character as a philosophical method. The appraisal of this other justification, however, is beyond the scope of this paper.

Now recall that the main claims of PhenoMed are not solely descriptive, i.e., they do not solely consist in describing or defining health, illness, their corresponding experiences, or singular illness experiences. There is a prescriptive or normative aspect to their claims, in that their philosophical work is meant to have a positive impact on clinical practice and medicine overall. The goal is for clinical practice to deliver better and more humane care as well as promoting empathy in medicine. It is important not to lose track of these prescriptive and normative claims because they help understanding the motivations and perhaps the reasons behind why PhenoMed is wary of naturalism. In brief, their normative project seems to be decisive in understanding such an attitude. In what follows, I argue that the disagreement over naturalism in PhenoMed is not solely epistemological but also ethical, hence turning the disagreement with naturalism into a disapproval of naturalism.

\subsection{Another aspect of the issue: the ethical disapproval of naturalism}

In the beginning of his recent book on naturalism, Andler distinguishes two types of disapproval in the naturalism versus anti-naturalism debate: a theoretical type of disapproval and a practical type of disapproval (Andler, 2016, pp. 22-29). Both sides of this distinction can helpfully characterise our case at hand, where PhenoMed appears to be wary of naturalism. The theoretical disapproval of naturalism is described by Andler as arguing that naturalist proponents are somehow misled by the success of science and tempted to apply its tools to expanding domains (2016, p. 24). Carel's warning that "[i]t is not enough to see illness as an entity in the world that can be studied with the tools of science" (Carel, 
2016, p. 1) is a good illustration of such a worry. But the crux of the issue is elsewhere, in the second type of disapproval described by Andler - the practical and ethical disapproval of naturalism. It is practical in the sense that it accuses naturalism of being responsible for certain consequences in the world. In the case of PhenoMed, the practical aspect of their critique is obvious: naturalism in medicine is accused of fostering inhumane (or at least, non-humane) clinical practices. Indeed, the prescriptive goal of PhenoMed is to replace these with more humane or humanistic care, notably by promoting empathetic practices. What is at stake, even in the more general debate between naturalism and antinaturalism, as Andler remarks, is that "the anti-naturalist accuses the naturalist of anti-humanism, and see in her a real moral enemy" (Andler, 2016, p. 27); ${ }^{9}$ in other words, naturalism is accused of belittling and stripping humans of their humanity $(2016$, p. 27). I argue that this practical and ethical disapproval is an important part of PhenoMed's ambiguous attitude towards naturalism and that it has not been recognised as such in the literature. Understanding this attitude as an ethical disapproval especially illuminates the prescriptive claims put forward by PhenoMed as well as the special methodological role that is devoted to phenomenology in its approach. It is because naturalism is believed to belittle humans by reducing them to their biological functions that PhenoMed urges the philosophy of medicine to focus on the multifaceted experience of illness and clinical practice. For instance, Carel argues that the sensitivity of the phenomenological method may "translate into an ethical sensibility: it may call on us to develop an openness to others grounded in a robustly critical self-reflective study of oneself" (Carel, 2016, p. 13). This ethical disapproval indeed reflects the values held by PhenoMed proponents, which among other emphasise the importance of the singular individual, with all its various idiosyncratic aspects, taking it as the basis to define what constitutes humanity. Carel thus emphasises that illness experiences "need to be studied in their particularity" adding that one important role of phenomenology is to "to attend to the individual and idiosyncratic experience of illness"10 (Carel, 2016, pp. 2-3).To a perceived reductionist view of humanity, proponents of PhenoMed respond with a comparatively inflationist approach, putting forward the "psychological, social, cognitive, emotional, existential, and temporal" aspects of humanity (Carel, 2011, p. 42). Moreover, the special aspect of the phenomenological method - the aspect that is believed to go past naturalism's shortcomings - is directly linked to these prescriptive goals. Whether this role given to phenomenology is on par with the traditional phenomenological method is left opened to question here.

\footnotetext{
${ }^{9}$ « Ce qu'il s'agit de comprendre ici, c'est le fait qu'Anat accuse Nat d'antihumanisme, et voit donc en lui un véritable ennemi moral. " $(2015,27)$

10 The second role of phenomenology is described by Carel as the study of the "systematic changes to the structure of experience brought about by illness" (Carel, 2016, pp. 2-3).
} 
If PhenoMed proponents keep clear of endorsing a modest form of naturalism, it may be in the fear of giving in to a corresponding modest view of humanity. It is true that some forms of naturalism have shaped themselves as anti-humanist, in the sense that they rejected for example the possibility of transcendental knowledge or the irreducibility of consciousness (Rouse, 2008). ${ }^{11}$ This is probably why many humanists endorse a form of anti-naturalism. ${ }^{12}$ However, a modest type of naturalism does not necessarily threaten the integrity of an understanding of humanity. There is room for humanistic form of naturalism. In other words, a naturalist view may perfectly be in a good position to defend humanity's own interests. Conversely, it is also possible for an anti-naturalist approach to be anti-humanist. For instance, a holistic non-biomedical view of medicine could also be very inhumane, in a way, if it were leading physicians to lie to their patients about the efficiency of their treatments. More simply, nothing in embracing naturalism in medicine logically implies inhumane medical practices. As Ernst Nagel wrote in 1954, in a more general context:

there is no incompatibility, whether logical or psychological, between maintaining that warranted knowledge is secured only through the use of a definite logical method, and recognising that the world can be experienced in many other ways than by knowing it.

$$
\text { (Nagel, 1954, p. 16) })^{13}
$$

According to Nagel, naturalism is in an even better position to deal with the "tragic aspects of life" (1954, p. 16). Indeed, although offering no "cosmic consolation" to the sufferings of human life, naturalism is not a philosophy of despair, precisely because, according to Nagel, it recognises the limits of what can be remediable. In brief, humanism and naturalism stand in two different logical "boxes", such that anti-naturalism and naturalism may both be anti-humanist or humanist positions. It could be that there are scientific naturalist movements in medicine that are anti-humanist - such movements do arguably exist outside medicine - however, whether this is the case in medicine hasn't been properly justified by PhenoMed. Overall, if PhenoMed's ethical disapproval of naturalism helps understanding the shifting context of their arguments, as well as the practical aspects of their claims, it faces significant issues nonetheless, and I would argue that it is the least justified aspect of their disagreement with naturalism so far.

\footnotetext{
${ }^{11}$ According to Joseph Rouse (2008), this is the case of what De Caro and MacArthur (2004) have characterised under the label "scientific naturalism" which he describes as "anti-humanism."

12 Indeed, one obvious interpretation of PhenoMed's wariness of naturalism is the historical anti-naturalism of the first phenomenologists themselves. In most cases, anti-naturalism in PhenoMed is, however, not spelled out by means of historical phenomenological arguments. This will be addressed in section 5 .

${ }^{13}$ Nagel adds that "[i]t is a matter of record that outstanding exponents of naturalism, (...), have exhibited an unequaled and tender sensitivity to the esthetic and moral dimensions of human experience; and they have been (...) vigorous defenders of the distinctive character of these values against facile attempts to reduce them to something else."
} 
Finally, it should be noted that PhenoMed has some room to argue against naturalism about the possibility of acquiring a special kind of knowledge from the first-person perspective (for instance, transcendental knowledge). However, this strategy would not be an ethical disapproval against naturalism in the name of humanism, it would be a philosophical disagreement with naturalism about the possible ways to acquire knowledge, which, however, remains to be done.

\section{Minding the gap to move forward: an agenda for future debates}

In what follows, I briefly lay out the possible ways by which PhenoMed may clarify their attitude towards naturalism. In doing so, I hope to give an agenda for future debates about naturalism in the phenomenology of medicine, but also more generally, in the philosophy of medicine and the medical humanities literature. Indeed, although this paper focuses on the case of PhenoMed, a similar rejection or suspicion of naturalism can be identified elsewhere, such that the clarifications I offer may be useful to those other approaches as well. Think for instance of holistic or normativist approaches which proceed under a similar anti-naturalistic banner.

The most important way for the proponents of PhenoMed to clarify their disagreement with naturalism is for them to distinguish the types of disagreement I sketched out: the theoretical disagreement and the ethical disapproval. In what follows, I will concentrate on the theoretical side of the disagreement and the way it may be made clearer. Indeed, it is not clear to me how an ethical disapproval of naturalism could be maintained in PhenoMed, without risking it to become an ideological prejudice. There are two corresponding options for PhenoMed to move forward: clarifying why they are wary of naturalism, by shaping a clearer critique of naturalism, or stop being wary of naturalism altogether and getting comfortable with it.

\subsection{The first option: clarifying why one ought to be wary of naturalism}

PhenoMed need to explicitly explain whose and what kind of naturalism - in the case of medicine or more generally - they aim to target and they need to do so in a way that does not reduce it to a strawman. They also need to lay out why criticising naturalism is important for their position: do they criticise naturalism in the search of a new definition of health and disease? Or does their criticism have another purpose? As mentioned before, an obvious way for PhenoMed to establish their position against naturalism would be to go back to the roots of anti-naturalism in the phenomenological tradition itself. Indeed, an important reason why phenomenologists such as Husserl were antinaturalist is that they believe that there is such a thing as transcendental knowledge. There are many transcendental arguments to be made against naturalism that PhenoMed could reuse to their benefits. PhenoMed would have to show, however, how these transcendental arguments fit in with their 
arguments related to illness and medicine. One issue with this path is that Carel, notably, explicitly let go of transcendentalism in her approach, deeming it unnecessary for phenomenology (Carel, 2011, p. 35). She thus writes that "for the purposes of describing the experience of illness, it is enough to consider the general features of illness without insisting on the transcendental nature of its features" (2011, p. 35). I leave open for now the question of whether PhenoMed retain, wish or need to retain transcendentalism in their approach.

Another interesting way for PhenoMed to clarify their position would be to target something like "scientific imperialism" or a tendency going with a certain form of scientific naturalism. For instance, Dupré has argued against such a "scientific imperialism" (1994, 2001). Dupré defines scientific imperialism as "the tendency to push a good scientific idea far beyond the domain in which it was originally introduced, and often far beyond the domain in which it can provide much illumination" (Dupré, 2001, p. 74). Interestingly, one of the examples studied by Dupré in his 1994 paper is medical and refers to what Dupré calls the imperialistic economist approaches to the epidemiology of AIDS. While noting that there is nothing wrong with the use of economic sciences to study the epidemiology of AIDS, Dupré argues that there is an issue, in that case, in the way some economists study and conceptualise human behaviour (both at the level of the assumptions and the methodology).Turning back to PhenoMed, in what way could biomedical sciences - medicine or one specific medical science - be similarly said imperialistic over clinical science? The example described by Dupré illustrates that parts of medical sciences themselves may be at the mercy of imperialistic approaches, for instance in his case study, economic science approaches. Are there scientific imperialistic approaches that specifically target the experience of illness (what seems to matter the most to proponents of PhenoMed)? If so, this would be an interesting way to spell out a criticism of scientific naturalism. Note that this kind of criticism would be compatible with some form of naturalism. This leads me to consider what seems to me a more promising way for PhenoMed to clarify their attitude towards naturalism: getting comfortable with it.

\subsection{The second option: getting comfortable with naturalism}

The second possible way of handling these issues surrounding naturalism is more convenient: giving up the critique of naturalism altogether and embracing some form of naturalism. As it stands, it does not appear to be crucial for PhenoMed to criticise and argue against naturalism. Especially if they do not want to keep phenomenology's transcendental approach (Carel, 2011, p. 35). They can stand together with naturalistic (and normativist) proponents at their side. Claims about the importance of subjective experiences of illness are compatible with naturalistic descriptions of disease. This is unsurprising since many proponents of the phenomenological approaches explicitly aim to solely 
augment naturalism. Doing so, they may commit to a non-stereotypical and modest form of naturalism, avoiding the risk of criticise a strawman or an arbitrary definition of biomedicine.${ }^{14}$ Indeed, there is room to engage in dialogue with naturalism, notably for instance, by taking a pluralistic stance (I am thinking here of pluralistic approaches in the philosophy of science, such as Longino, 1990; Solomon, 2015). Doing so, proponents of PhenoMed could argue that phenomenology is one among other methods useful in medicine. The claim about the special character of phenomenology would be weakened, but less open to criticism. PhenoMed could bring forward the importance of illness narratives and idiosyncratic experiences into the table, and offer phenomenological inspired tools to deal with such narratives, doing so without committing to anti-naturalism, or even naturalism for that matter. ${ }^{15}$

Regarding the tendency of PhenoMed to locate their anti-naturalism in the context of the debate about the concepts of health and disease, solutions are also available. Very recent works in that debate have steered away from the strict opposition between naturalism and normativism (see Kingma, 2014; Chin-Yee \& Upshur, 2017), some have defended hybrid theories (Traykova, 2017), and finally some have argued in favour of redefining altogether what should count as a naturalist approach to health and disease (Lemoine, 2015). If this path proves unsatisfactory, there is also room to draw inspiration from the phenomenological traditions that engage with naturalism. Canguilhem's work, for instance, is firmly naturalistic. ${ }^{16}$ Although his work has been quoted in Carel's most recent book (2016), it hasn't been connected to its naturalistic grounding. In Canguilhem's approach, the experience of illness is described and understood from a biological and, at the same time, normative point of view; Canguilhem arguing that there are some values within the biological. Canguilhem would be thus a good starting point to avoid falling unwittingly into embracing dualism once again. Sholl has thus notably offered a normative and biological understanding of function and health inspired by Canguilhem (Sholl, 2016), spelling out what he refers to as "surnaturalism."17

\footnotetext{
${ }^{14}$ Epistemological naturalism could be a type of modest naturalism. Pluralistic types of naturalism are also a possibility.

${ }^{15}$ See for instance (Kidd, 2017) for a discussion of the importance of examples in ethics, which does not rely on a criticism of naturalism.

${ }^{16}$ His work has been referred to as "anti-reductionist naturalism" (Giroux, 2010), "critical naturalism" (Sholl, 2012) and "surnaturalism" (Sholl, 2016).

${ }_{17}$ A similar proposition has been made by Luca Vanzago, in a review of Carel's 2016 book (Vanzago, 2017). According to Vanzago, more work needs to be done to "deepen the nexus between bodily experience and bodily life, along the lines suggested by Merleau-Ponty in his lectures on nature at the Collège de France in the midfifties. Otherwise we risk remaining on the level of consciousness, no matter how embodied this is." Vanzago also suggests the works by Hans Jonas (Jonas, 1966), where biology is looked at from a phenomenological point of view.
} 
At the very beginning of her last work, Carel describes the need for "a view of personhood as embodied, situated, and enactive" in order to explain and understand the full illness experience (2016, p. 14). Although she then moves on to appeal to Husserl, Merleau-Ponty and Sartre, the filiation with more recent attempts at bridging phenomenology and naturalism, by which I mean enactive and embodied approaches to consciousness (Petitot, Varela, Pachoud, \& Roy, 1999; Varela, Maturana, \& Uribe, 1974), is almost explicit. This could be a path for PhenoMed towards embracing naturalism. ${ }^{18}$ In an attempt to naturalised phenomenology of illness, PhenoMed would need to justify the application of enactivism from the cognitive sciences to medical science and practice. The difficulty is that to do so would require a reflection on how philosophical questions about consciousness (the problem of the explanatory gap, for instance) have an impact on the definition or understanding of illness.

In any case, even without entering this debate, embracing a naturalistic philosophical approach could be useful for PhenoMed in other ways: for instance, it would give their approach concrete targets in health systems, instead of descriptions of biomedical models prone to criticism. The targets then would not be a philosophical position or a philosopher, but the way health systems are organised in a country. Finally, these targets may prove useful in directing in a more straightforward way any type of ethical disapproval. These are only a few suggestions among the many ways the issues put forward in this paper could be tackled. Overall, I hope to have convinced the reader that PhenoMed has everything to gain in clarifying their attitude towards naturalism and in starting a dialogue with the approach.

\section{Concluding remarks: from PhenoMed to humanistic approaches in medicine}

In this paper I identified what I called a wary attitude towards naturalism in PhenoMed's approaches. Having illustrated how important this attitude is for PhenoMed, I turned to argue that two distinct aspects of this attitude should be distinguished, a philosophical disagreement and a moral disapproval of naturalism, both of which face issues. Having said that, I also illustrated how PhenoMed may clarify their position towards naturalism, in particular by embracing some form of it, leaving room for a renewed debate with some parts of naturalism.

It was especially important to characterise and understand PhenoMed's position towards naturalism because it might be the main reason why phenomenology has been introduced in the field in the first place. Introducing phenomenology in a field because of one's anti-naturalistic feelings is

\footnotetext{
${ }^{18}$ However, naturalising phenomenology is such a hugely debated project (see for instance Zahavi, 2004) that is may not be the most practical strategy for PhenoMed to follow.
} 
done in many places (think of such fields as humanistic psychology, phenomenological sociology, phenomenological anthropology, phenomenology and psychiatry, phenomenology in nursing). As Tania Gergel $(2012,2013)$ has argued concerning phenomenology in nursing studies, quite often phenomenology in these cases, has been unshaped and watered down to serve specific purposes (quite often, emphasising subjective experience in a particular field), using the apparent complexity of phenomenology as a convenient argument to go around naturalism. Although the case of PhenoMed is considerably different, the context of the philosophy of medicine is important: PhenoMed is not the only approach positioning itself against naturalism in the philosophy of medicine, it is but one part of a broader trend aiming at humanising medicine. The wider wary feeling against naturalism in this humanistic trend may be said to face similar issues, although of course, other works would be needed to make that argument. In urging to clarify one's position towards naturalism, the purpose is not solely a defence of naturalism, but a clarification of what humanising medicine could amount to. For instance, it doesn't seem that it could amount to morally disapproving naturalism, for that would risk falling into an ideological rather than philosophical critique.

\section{References}

Andler, D. (2016). La silhouette de l'humain. Quelle place pour le naturalisme dans le monde d'aujourd'hui ? Paris: Gallimard.

Boorse, C. (1975). On the distinction between disease and illness. Philosophy \& Public Affairs, 5(1), 4968.

Carel, H. (2008). Illness: the cry of the flesh. Stocksfield: Acumen.

Carel, H. (2011). Phenomenology and its application in medicine. Theoretical Medicine and Bioethics, 32(1), 33-46.

Carel, H. (2012). Phenomenology as a resource for patients. Journal of Medicine and Philosophy, 37(2), 96-113.

Carel, H. (2016). The phenomenology of illness. Oxford: Oxford University Press.

Carel, H. (2017). Phenomenology and hermeneutics in Medicine. In The Routledge Companion to Philosophy of Medicine (Miriam Solomon, Jeremy R. Simon, Harold Kincaid). Routledge.

Chin-Yee, B., \& Upshur, R. E. G. (2017). Re-evaluating concepts of biological function in clinical medicine: towards a new naturalistic theory of disease. Theoretical Medicine and Bioethics, 38(4), 245-264.

De Caro, M., \& MacArthur, D. (2004). Naturalism in question (Harvard University Press). Cambridge.

Dupré, J. (1994). Against Scientific Imperialism. PSA: Proceedings of the Biennial Meeting of the Philosophy of Science Association, 1994, 374-381.

Dupré, J. (2001). Human Nature and the Limits of Science. Oxford University Press.

Engel, G. L. (1977). The need for a new medical model: a challenge for biomedicine. Science, 196(4286), 129-136.

Foot, P. (1958). IV.-MORAL ARGUMENTS. Mind, LXVII(268), 502-513.

Gergel, T. L. (2012). Medicine and the individual: is phenomenology the answer? Journal of Evaluation in Clinical Practice, 18(5), 1102-1109.

Gergel, T. L. (2013). Illness perception, time perception and phenomenology - an extended response to Borrett. Journal of Evaluation in Clinical Practice, 19(3), 501-508.

Giroux, É. (2010). Après Canguilhem : définir la santé et la maladie. Paris: Presses Universitaires de France - PUF. 
Jonas, H. (1966). The Phenomenon of Life: Toward a Philosophical Biology. New York: Harper \& Row, Publishers Inc.

Kidd, I. J. (2017). Exemplars, ethics, and illness narratives. Theoretical Medicine and Bioethics, 38(4), 323-334.

Kingma, E. (2014). Naturalism about health and disease: adding nuance for progress. The Journal of Medicine and Philosophy, 39(6), 590-608.

Legrand, D. (2017). The living body and the lived body in the clinical encounter: how does the body shape ethical practice. In Handbook of the Philosophy of Medicine (Schramme, Thomas, Edwards, Steven). Netherlands: Springer.

Lemoine, M. (2015). The Naturalization of the Concept of Disease. In Classification, Disease and Evidence (pp. 19-41). Springer, Dordrecht.

Longino, H. E. (1990). Science as social knowledge: values and objectivity in scientific inquiry. Princeton: Princeton University Press.

Marcum, J. A. (2008). Reflections on humanising biomedicine. Perspectives in Biology and Medicine, 51(3), 392-405.

Nagel, E. (1954). Naturalism Reconsidered. Proceedings and Addresses of the American Philosophical Association, 28, 5-17.

Petitot, J., Varela, F. J., Pachoud, B., \& Roy, J.-M. (1999). Naturalizing phenomenology: Issues in contemporary phenomenology and cognitive science. Stanford: Stanford University Press.

Rose, N. (2007). Beyond medicalisation. The Lancet, 369, 700-01.

Rouse, J. (2008). George Gasser (ed.) How is naturalism. Book review. Notre Dame Philosophical Reviews.

Ryle, G. (1968). The Thinking of Thoughts: What is 'Le Penseur' Doing? In Collected Papers, Volume 2. London: Hutchinson.

Schramme, T., \& Edwards, S. (2017). Handbook of the philosophy of medicine. Dordrecht: Springer.

Sholl, J. (2012). The Knowledge of Life in Canguilhem's Critical Naturalism. Pli: The Warwick Journal of Philosophy, 23, 107-127.

Sholl, J. (2015). Putting phenomenology in its place: some limits of a phenomenology of medicine. Theoretical Medicine and Bioethics, 36(6), 391-410.

Sholl, J. (2016). Contextualizing Medical Norms: Georges Canguilhem's Surnaturalism. In Naturalism in the Philosophy of Health (pp. 81-100). Springer, Cham.

Solomon, M. (2015). Making medical knowledge. Oxford: Oxford University Press.

Solomon, M., Kincaid, H., \& Simon, J. (2017). The routledge companion to philosophy of medicine. Routledge.

Stempsey, W. E. (2008). Philosophy of Medicine Is What Philosophers of Medicine Do. Perspectives in Biology and Medicine, 51(3), 379-391.

Svenaeus, F. (2000). The hermeneutics of medicine and the phenomenology of health: steps towards a philosophy of medical practice. Dordrecht: Kluwer Academic Publishers.

Svenaeus, F. (2001). The phenomenology of health and illness. In Handbook of phenomenology of medicine (S. K. Toombs). Springer Netherlands.

Svenaeus, F. (2009). The phenomenology of falling ill: an explication, critique and improvement of Sartre's theory of embodiment and alienation. Human Studies, 32(1), 53-66.

Svenaeus, F. (2013). Naturalistic and phenomenological theories of health: distinctions and connections. Royal Institute of Philosophy Supplements, 72(Supplement-1), 221-238.

Svenaeus, F. (2014). The phenomenology of empathy in medicine: an introduction. Medicine, Health Care and Philosophy, 17(2), 245-248.

Svenaeus, F. (2017). Phenomenological Bioethics: Medical Technologies, Human Suffering, and the Meaning of Being Alive (Routledge). Retrieved from

Toombs, S. K. (1987). The meaning of illness: a phenomenological approach to the patient-physician relationship. Journal of Medicine and Philosophy, 12(3), 219-240.

Toombs, S. K. (1988). Illness and the paradigm of lived body. Theoretical Medicine and Bioethics, 9(2).

Toombs, S. K. (2001). Handbook of phenomenology and medicine. Dordrecht: Kluwer Academic. 
Traykova, A. (2017). Optimizing hybridism: a critique of naturalist, normativist and phenomenological accounts of disease in the philosophy of medicine. Durham theses, Durham University. Available at Durham E-Theses Online: http://etheses.dur.ac.uk/12312/.

Vanzago, L. (2017). [Review of Review of Phenomenology of IIIness, Havi Carel, 2016, by H. Carel]. Notre Dame Philosophical Reviews.

Varela, F., Maturana, H., \& Uribe, R. (1974). Autopoiesis: The organization of living systems, its characterisation and a model. Biosystems, 5(4), 187-196.

Williams, B. (1985). Ethics and the Limits of Philosophy (1 edition). London: Routledge.

Zahavi, D. (2004). Phenomenology and the project of naturalization. Phenomenology and the Cognitive Science, 3. 